\title{
Importance of antimicrobial stewardship to the English National Health Service
}

This article was published in the following Dove Press journal:

Infection and Drug Resistance

30 May 2014

Number of times this article has been viewed

\section{Jill Dixon}

\section{Christopher JA Duncan}

Department of Infectious Diseases and Tropical Medicine, Royal Victoria Infirmary, Queen Victoria Road, Newcastle upon Tyne, UK
Correspondence: Christopher JA Duncan Department of Infectious Diseases and Tropical Medicine, Royal Victoria Infirmary, Queen Victoria Road, Newcastle upon Tyne, NEI 4LP, UK Tel +44 019 I233 616I extension 23710 Email chrisduncan@doctors.net.uk
Abstract: Antimicrobials are an extremely valuable resource across the spectrum of modern medicine. Their development has been associated with dramatic reductions in communicable disease mortality and has facilitated technological advances in cancer therapy, transplantation, and surgery. However, this resource is threatened by the dwindling supply of new antimicrobials and the global increase in antimicrobial resistance. There is an urgent need for antimicrobial stewardship (AMS) to protect our remaining antimicrobials for future generations. AMS emphasizes sensible, appropriate antimicrobial management for the benefit of the individual and society as a whole. Within the English National Health Service (NHS), a series of recent policy initiatives have focused on all aspects of AMS, including best practice guidelines for antimicrobial prescribing, enhanced surveillance mechanisms for monitoring antimicrobial use across primary and secondary care, and new prescribing competencies for doctors in training. Here we provide a concise summary to clarify the current position and importance of AMS within the NHS and review the evidence base for AMS recommendations. The evidence supports the impact of AMS strategies on modifying prescribing practice in hospitals, with beneficial effects on both antimicrobial resistance and the incidence of Clostridium difficile, and no evidence of increased sepsis-related mortality. There is also a promising role for novel diagnostic technologies in AMS, both in enhancing microbiological diagnosis and improving the specificity of sepsis diagnosis. More work is needed to establish an evidence base for interventions to improve public and patient education regarding the role of antibiotics in common clinical syndromes, such as respiratory tract infection. Future priorities include establishing novel approaches to antimicrobial management (eg, duration of therapy, combination regimens) to protect against resistance and working with the pharmaceutical industry to promote the development of new antimicrobials.

Keywords: antimicrobial resistance, antibiotics, National Health Service, methicillin-resistant Staphylococcus aureus, Clostridium difficile, prescribing

\section{Introduction}

Alongside vaccines and public health measures to control transmission of communicable diseases, antibiotics have helped to dramatically reduce mortality from infectious disease during the 20 th century. ${ }^{1}$ This success generated a sense of complacency among some figures in public health and academia in the 1960s and 1970s. ${ }^{2}$ As Sir Frank Burnett, in accepting his Nobel prize for medicine in 1962, put it: "One can think of the middle of the twentieth century as the end of one of the most important social revolutions in history, the virtual elimination of the infectious diseases as a significant factor in social life." ${ }^{3}$ However, the enduring global challenge of pathogens such as influenza, tuberculosis, and malaria, as well as the emergence of human 
immunodeficiency virus, means that infectious disease remains an important problem. ${ }^{4}$

The real value of antibiotics goes beyond simply preventing death and illness due to infection, in that antibiotics also permit the serious iatrogenic assault on the immune system occurring in cancer treatment or organ transplantation and have helped to keep surgical complication rates down. ${ }^{5}$ Therefore, antibiotics are an extremely valuable resource across the spectrum of modern medicine. ${ }^{6}$ However, the supply of new antibiotics has slowed dramatically, with only one or two agents targeting Gram-negative pathogens likely to be brought to market in the next decade. ${ }^{7}$

\section{Antimicrobial stewardship}

There is an urgent need to protect our current antimicrobial drugs for future generations. ${ }^{8}$ Antimicrobials can be conserved by judicious use to limit the development of antimicrobial resistance (AMR); ${ }^{9}$ this is the core component of antimicrobial stewardship (AMS). ${ }^{10}$ Additional benefits of AMS include preventing the selection of opportunistic pathogens such as Clostridium difficile, ${ }^{11}$ limiting exposure to toxicities associated with misuse of antimicrobials, ${ }^{10}$ and direct economic savings through reduced complication rates and antimicrobial consumption. ${ }^{12}$ AMS emphasizes sensible, appropriate antimicrobial management for the benefit of the individual and society as a whole. ${ }^{5,13}$

\section{Antimicrobial resistance}

There is a clear role for AMS in controlling AMR. Microorganisms invariably develop resistance in response to the evolutionary pressure exerted upon them by exposure to antimicrobials. ${ }^{14}$ This fact was recognized by Sir Alexander Fleming in his initial studies of the antibiotic properties of the Penicillium fungus. He cautioned, in his Nobel prize acceptance speech in 1945, that misuse of penicillin could contribute to development of AMR which could in turn compromise its usefulness. The history of treatment for Neisseria gonorrhoeae illustrates this point; the gonococcus has sequentially developed resistance against most antimicrobial agents to which it has been exposed, including sulfonamides, penicillin, quinolones, and now some cephalosporins, ${ }^{13}$

Table I ESKAPE pathogens

\begin{tabular}{ll}
\hline Gram-positive & Gram-negative \\
\hline Enterococcus faecium & Klebsiella species \\
& Acinetobacter baumannii \\
Staphylococcus aureus & Pseudomonas aeruginosa \\
& Enterobacter species and Escherichia coli \\
\hline
\end{tabular}

Note: Data from Boucher et al. ${ }^{16}$ leaving multidrug-resistant $N$. gonorrhoeae isolates for which there are very few therapeutic options. ${ }^{15}$

This fearsome prospect of untreatable infection also applies to several other organisms. The Infectious Diseases Society of America has termed the main culprits the "ESKAPE pathogens"16 (Table 1), but the biggest global concern is AMR in Gram-negative bacteria. Enterobacteriaceae such as Escherichia coli or Klebsiella species that are resistant to all but one or two antimicrobials have evolved as a consequence of extremely high levels of antibiotic exposure in several parts of the world, including Asia and the Middle East. ${ }^{17}$ Infections with these multidrug-resistant organisms are associated with approximately two-fold higher mortality rates and considerably prolonged hospital admissions. ${ }^{17}$ In 2009, the European Centre for Disease Prevention and Control estimated that AMR costs the European Union $€ 1.5$ billion in health care expenses and lost productivity per year. ${ }^{18}$ Nosocomial transmission has caused outbreaks in health care facilities, and international travel has facilitated global dissemination. ${ }^{17} \mathrm{~A}$ history of hospitalization overseas has become a personal risk factor for acquisition of multidrugresistant organisms. ${ }^{19}$ In a recent survey, approximately one third of healthy travelers to Asia became asymptomatically colonized with multidrug-resistant Enterobacteriaceae despite low levels of health care contact. ${ }^{20}$ Such asymptomatic carriage is also significantly higher in people in the UK from certain demographic groups with links to high incidence regions. ${ }^{21}$

However, there is cause for optimism that this threat can be contained. Some European countries, such as Sweden, have pioneered stewardship programs that have successfully reduced antibiotic use and kept AMR rates low. ${ }^{9}$ An AMS program in Scotland has had an important impact

Table 2 UK 5 year antimicrobial resistance strategy 20I3-20I8

\begin{tabular}{ll}
\hline Strategic aims & Improve the knowledge and understanding of AMR \\
& Conserve and steward the effectiveness of existing \\
treatments & Stimulate the development of new antibiotics, \\
& diagnostics, and novel therapies \\
Seven key areas & Improving infection prevention and control practices \\
for action & Optimizing prescribing practice \\
& Improving professional education, training, and \\
& public engagement \\
& Developing new drugs, treatments, and diagnostics \\
& Better access to and use of surveillance data \\
& Better identification and prioritization of AMR \\
research needs & Strengthened international collaboration
\end{tabular}

Note: Adapted from Department of Health, Department for Environment, Food and Rural Affairs. UK Five Year Antimicrobial Resistance Strategy 20I3-20I8. Available from:https://www.gov.uk/government/uploads/system/uploads/attachment_data/file/ 244058/20130902_UK_5_year_AMR_strategy.pdf. ${ }^{23}$

Abbreviation: $A M R$, antimicrobial resistance. 
on antimicrobial consumption and $C$. difficile rates. ${ }^{22}$ AMS programs also appear to have had a significant impact in the English hospital setting. ${ }^{7}$ The incidences of both methicillinresistant Staphylococcus aureus and C. difficile peaked in the mid 2000s, and it is believed that a combination of restrictive antimicrobial policies and better infection prevention and control practices (eg, source isolation and handwashing) were responsible for the decreasing incidence of both infections, ${ }^{5}$ although it is not clear which of these interventions had the dominant role. At the global level, the problem of AMR in England is comparatively minor at present. However, with a relatively narrow focus on methicillin-resistant $S$. aureus and C. difficile, the growing problem of bacteremia due to other multidrug-resistant organisms has been largely ignored. ${ }^{?}$

AMR is an emergent threat to health care delivery within the National Health Service (NHS) in England. ${ }^{5}$ A multiplicity of government documents, recommendations, and position statements on AMS to address AMR in the English NHS have been produced over the last few years. Here we provide a timely summary of these publications to help clarify the current position and importance of AMS to the NHS in England. We outline the evidence base underpinning the AMS recommendations, and conclude with a discussion of future priorities.

\section{Antimicrobial stewardship initiatives in the NHS}

Concerns regarding the rise of AMR and the priority of AMS were recently highlighted by the Chief Medical Officer, Dame Sally Davies, in her annual report of 2011, published in March 2013. ${ }^{5}$ This report received a lot of attention and provided much needed focus for AMS leadership. ${ }^{7}$ The report addressed four broad areas of AMS:13

- Concerns about global AMR

- The need to raise awareness and education about AMR among the public and within the NHS

- The need for better surveillance systems for AMR

- The need to improve diagnostics.

In parallel with the Chief Medical Officer's report, a UK pan-governmental strategy and action plan for AMR has been recently published (see Table 2 ). ${ }^{23}$ However, awareness of AMR in the UK is not a recent development; a series of reports and policy initiatives has addressed AMR in the NHS over the last two decades, as summarized in Table 3. "The Path of Least Resistance" (1998) ${ }^{24}$ first outlined the AMS imperatives for the NHS. Introducing several stewardship themes that are recognizable in subsequent reports, it highlighted the need for antimicrobial prescribing to be evidence-based and supported by national formularies, and emphasized the need
Table 3 Key antimicrobial stewardship initiatives in the National Health Service

\begin{tabular}{|c|c|c|}
\hline Report & Year & Agency \\
\hline The Path of Least Resistance & 1998 & $\begin{array}{l}\text { Medical Advisory } \\
\text { Committee }\end{array}$ \\
\hline $\begin{array}{l}\text { UK Antimicrobial Resistance } \\
\text { Strategy and Action Plan }\end{array}$ & 2000 & Department of Health \\
\hline $\begin{array}{l}\text { Winning ways: Working } \\
\text { together to reduce Healthcare } \\
\text { Associated Infection in England }\end{array}$ & 2003 & Department of Health \\
\hline The Health Act & 2006 & Department of Health \\
\hline $\begin{array}{l}\text { Saving Lives: Reducing Infection, } \\
\text { Delivering Clean and Safe Care }\end{array}$ & 2007 & Department of Health \\
\hline $\begin{array}{l}\text { Health and Social Care Act: a Code } \\
\text { of Practice on the Prevention and } \\
\text { Control of Infections }\end{array}$ & 2008 & Department of Health \\
\hline TARGET toolkit & 2009 & $\begin{array}{l}\text { Antimicrobial Stewardship } \\
\text { in Primary Care }\end{array}$ \\
\hline Start Smart then Focus & 2012 & $\begin{array}{l}\text { Advisory Committee on } \\
\text { Antimicrobial Resistance } \\
\text { and Healthcare } \\
\text { Associated Infection }\end{array}$ \\
\hline $\begin{array}{l}\text { English Surveillance Programme } \\
\text { for Antimicrobial Utilization } \\
\text { and Resistance }\end{array}$ & 2013 & Public Health England \\
\hline
\end{tabular}

for antimicrobial prescribing to take a more prominent place in medical education, to utilize the expertise of infection specialists, and for resources to be directed towards research into developing strategies to combat AMR. ${ }^{24}$ Following this, the UK Department of Health produced several reports on AMR/ AMS, starting with the first UK "Antimicrobial Resistance Strategy and Action Plan" in 2000. ${ }^{25}$ The Health and Social Care Act $2008^{26}$ provided a framework for the Care Quality Commission to objectively measure the quality of health care provision, and specifically included AMS outcomes. Criterion 9 states: "Procedures should be in place to ensure prudent prescribing and antimicrobial stewardship."

There should be an ongoing program of audit, revision, and update. In health care, this is usually monitored by the antimicrobial management team or local prescribing advisors. To provide practical guidance for NHS providers, the Antimicrobial Stewardship in Primary Care collaboration was formed in 2009. This multiagency collaboration produced a multifaceted AMS intervention for primary care that was launched in 2012. The Treat Antibiotics Responsibly, Guidance and Education Toolkit (TARGET) ${ }^{27}$ contains evidence-based resources for clinician and patient education, as well as specific antimicrobial guidance and self-assessment and audit tools. Also in 2012, the Department of Health's Advisory Committee on Antimicrobial Resistance 
and Healthcare Associated Infection produced the "Start Smart and Focus" guidance ${ }^{18}$ to provide a framework for best antimicrobial prescribing practice. Included within Start Smart and Focus is the Acute Hospital's Assessment Tool, ${ }^{28}$ an evidence-based checklist for AMS assessment and audit. Overall, these publications aim to standardize the practice of AMS across the NHS in England in both primary and secondary care settings.

\section{Antimicrobial prescribing in the NHS}

It is challenging to accurately assess current prescribing patterns across the NHS in England. Whilst the Health and Social Care Information Centre monitors antimicrobial dispensing data in primary care, there is no routine public reporting of antimicrobial use in hospitals. ${ }^{29}$ For this, we must rely on intermittent antibiotic point prevalence surveys, such as that done in 2011 by the Health Protection Agency. ${ }^{5}$ Within the NHS, most antimicrobial prescribing (up to $80 \%$ ) happens in primary care. However, despite awareness of the problem of resistance and the raft of AMS reports discussed above (Table 3), there was a 16\% increase in antimicrobial prescriptions in primary care between 2002 and 2012. ${ }^{29}$ The "NHS Atlas of Variation in Health Care" also describes a three-fold variation in quinolone prescriptions and an 18-fold variation in cephalosporin prescriptions across primary care trusts in England in 2010. ${ }^{18}$ Such regional variation also applies to inpatient antimicrobial prescriptions (which vary in the range of $29 \%-39.9 \%$ for inpatients) and seems not to be driven solely by demographic factors or regional variation in burden of disease. ${ }^{5}$

\section{Surveillance}

More detailed understanding of patterns of antimicrobial use will be of central importance when directing and assessing the impact of AMS programs in England. As a result, Public Health England has developed the English Surveillance Programme for Antimicrobial Utilization and Resistance to monitor antimicrobial prescribing and resistance in primary and secondary care. ${ }^{29}$ The English Surveillance Programme for Antimicrobial Utilization and Resistance also has the remit to develop quality measures and methods to monitor unintended outcomes of AMS and educational/behavioral interventions. ${ }^{29}$

\section{Education and training}

The desire for more training in antimicrobial prescribing has been identified in surveys of both doctors in training ${ }^{30}$ and medical students. ${ }^{31}$ Trainee doctors generally view comprehensive antimicrobial prescribing guidelines positively, ${ }^{30}$ although surveys continue to show that when prescriptions are noncompliant with guidelines, the antibiotic choice tends to be broader spectrum but not more appropriate to the organism, ${ }^{32}$ suggesting that efforts to improve adherence with guidelines are warranted. Growing recognition that the principles of antimicrobial prescribing and stewardship are central to the practice of medicine in the UK has led to the development of specific antimicrobial prescribing competencies within a 2012 report entitled "A single competency framework for all prescribers", 33 developed by the National Prescribing Centre on behalf of the National Institute for Clinical Excellence, which has been endorsed by the General Medical Council and the Academy of Medical Royal Colleges. To complement the National Prescribing Centre competency framework, five specific antimicrobial prescribing and stewardship competencies have been recently released by the Advisory Committee on Antimicrobial Resistance and Healthcare Associated Infection. ${ }^{34}$ These cover infection prevention and control, AMR, antimicrobial prescribing, AMS, and monitoring and learning. The need for better education and training does not just apply to health care professionals. As consumers of antimicrobials, it is vital to engage patients and members of the public in AMS campaigns.

\section{Public engagement}

Public misconceptions about the role of antibiotics in viral infections ${ }^{35}$ indicate a need for better education, and surveys have shown that among various reasons cited by practitioners for inappropriate antibiotic prescriptions, patient expectation was highly influential. ${ }^{36,37}$ Annual European Antibiotic Awareness Days (EAAD) aim to improve public understanding about the appropriate role for antibiotics in common clinical scenarios. ${ }^{38}$ However, in a recent survey performed in conjunction with EAAD, approximately $35 \%$ of those surveyed in the UK were unaware that antibiotics have no effect in viral infection. ${ }^{38}$ Some interventions such as the English 2008 poster-based EAAD educational program had a negligible impact on antimicrobial knowledge or consumption. ${ }^{39}$ However, other simple practical measures such as an interactive booklet on respiratory infections in children supplied in primary care have been shown to significantly reduce antibiotic prescriptions without reducing parental satisfaction; ${ }^{40}$ this booklet is included in the TARGET toolkit. ${ }^{27}$ Whilst the need for better patient education about the role of antibiotics is widely acknowledged, $5,12,13$ there is also a need for more evidence-based guidance about how best to achieve this. However, the main focus 
of AMS is on reducing antimicrobial prescribing by health care professionals, and we summarize evidence for such interventions below.

\section{Evidence base for AMS interventions Primary care}

A variety of heterogeneous AMS interventions in the primary care setting have been evaluated. ${ }^{41}$ The main objective is to reduce antimicrobial prescribing for various infections, particularly respiratory tract infection (which is most commonly viral $^{41}$ ) as well as uncomplicated urinary tract infection and otitis media, or reducing the prescription of specific agents. A previous Cochrane review ${ }^{42}$ indicated that multifaceted interventions tailored to precise target populations were most likely to have significant effects on prescribing. Recent randomized controlled trials have evaluated multifaceted interventions ${ }^{43,44}$ with positive effects on reducing antibiotic prescribing rates. However, few studies have been sufficiently powered, designed, or tested interventions with sufficient effect sizes to show an impact on AMR. ${ }^{42}$

\section{Secondary care}

The effectiveness of AMS interventions on inpatient prescribing has been the subject of a recently updated Cochrane systematic review and meta-analysis. ${ }^{45}$ Intervention studies have evaluated the effect of persuasive interventions (including circulation of educational material, educational meetings, and audit and feedback) and restrictive measures (including reporting selective antimicrobial sensitivities, formulary restrictions, and mandatory prior infection specialist approval for certain drugs) in reducing inappropriate antimicrobial prescriptions. The majority of interventions (in $84 \%$ of studies) focused on the antimicrobial prescribed, whereas the remainder addressed whether or not antibiotics should be prescribed at all. Both restrictive and persuasive interventions were effective in randomized controlled trials (median effect size $40.5 \%$ versus $24.7 \%$, respectively). In a meta-analysis of 52 studies, restrictive interventions had significantly greater impact on prescribing outcomes at one month (32\%, 95\% confidence interval [CI] 2-61, $P=0.03)$ and on microbial outcomes at 6 months (53\%, 95\% CI 31-75, $P=0.001)$ but there were no significant differences at 12 or 24 months. Several beneficial outcomes were associated with reduced antimicrobial prescribing (regardless of how it was achieved), such as reduced $C$. difficile, methicillinresistant $S$. aureus, and extended spectrum beta-lactamase
Enterobacteriaceae rates. In addition, whilst there was no clinical evidence of increased mortality in nine studies aimed at reducing antibiotic exposure, four studies focusing on optimizing prescribing for community-acquired pneumonia showed a significant improvement in mortality (risk ratio $0.89,95 \%$ CI $0.82-0.97$ ). Overall, these data indicate that AMS interventions are effective and evidence-based, and support restrictive interventions when short-term improvements are required.

\section{Diagnostics}

Delay in administering effective antibiotics results in stepwise increases in mortality resulting from bacterial sepsis. ${ }^{46}$ From the perspective of AMS this presents a paradox, given that as AMR becomes more prevalent the need for clinicians to use empirical broad spectrum antibiotics in patients with severe sepsis will become greater, driving selection of resistant microorganisms and exacerbating the problem. Strategies to improve the diagnosis of serious infection with multidrugresistant organisms are a particular focus of AMS programs to guide the appropriate use of broad-spectrum therapy and avoid unnecessary antibiotic exposure. The role for novel diagnostic technologies lies in rapid identification of causative organisms (which permits targeted, narrow-spectrum therapy), as well as in improving the specificity of sepsis diagnosis (given that many patients with a systemic inflammatory response do not have serious bacterial infection and therefore do not require antibiotic therapy). Developments in this field are the subject of a recent review. ${ }^{12}$

\section{Biomarkers}

The use of biomarkers has been shown to aid the clinical diagnosis of infection and to reduce unnecessary antibiotic prescriptions. ${ }^{5}$ For example, the inclusion of the biomarker procalcitonin in an antibiotic management algorithm has been shown in randomized controlled trials ${ }^{47}$ and in pragmatic clinical trials ${ }^{48}$ to safely reduce the frequency and duration of antibiotic therapy for suspected lower respiratory tract infection, and to enhance de-escalation of broad-spectrum antibiotics in cancer patients ${ }^{49}$ and critical care patients ${ }^{50}$ with infection. In a recent meta-analysis, procalcitonin combined with careful clinical assessment had a sensitivity of 0.77 and specificity of 0.79 for the diagnosis of sepsis compared with systemic inflammatory response of noninfective etiology, ${ }^{51}$ and preliminary studies suggest it can be used safely in NHS medical admission settings. ${ }^{52}$ The use of C-reactive protein as a biomarker in primary care AMS initiatives has shown efficacy in reducing antimicrobial prescriptions (reviewed in Moore ${ }^{41}$ ). 
Algorithms incorporating newer biomarkers, alone or in combination, are also under investigation, ${ }^{12}$ but more data are required before their definitive role can be established.

\section{Rapid microbiological diagnosis}

Current microbiological diagnosis is inefficient, with a minimum lag of 48 hours between the isolate reaching the laboratory and accurate organism identification. Molecular techniques have the potential to greatly speed up microbiological diagnosis and could also be used to detect genomic resistance, thus reducing exposure to unnecessary broadspectrum antibiotics. With sufficient sensitivity, they could also play a part in determining whether antibiotics need to be prescribed or not. These techniques broadly involve either proteomic or genomic methods.

Matrix-assisted laser desorption/ionization time-of-flight mass spectrometry (MALDI-TOF MS) detects the proteomic signature of an array of pathogens, and can yield diagnostic information in a matter of minutes. ${ }^{53}$ The utility of MALDITOF in the AMS setting has been demonstrated in proof of concept studies. ${ }^{54}$ However, technical issues currently preclude its more widespread application, such as difficulties in distinguishing certain bacterial species and problems identifying polymicrobial infections. ${ }^{12}$

Additional molecular techniques, such as nucleic acid amplification or nucleic acid hybridization, are in clinical use for pathogen detection (eg, identifying $N$. gonorrhoeae, Chlamydia trachomatis, C. difficile, and several other pathogens). Rapid nucleic acid amplification kits can also identify resistance mutations, such as the mecA gene in methicillin-resistant $S$. aureus. ${ }^{55}$ Next-generation whole genome sequencing has greater potential applicability to AMS, in view of its ability to simultaneously identify several pathogens as well as potential resistance mutations, as well as its ability to provide early indications of outbreaks through analysis of the relatedness of pathogen genomes in different patients. ${ }^{56}$ However, much work remains before these technologies are available for cost-effective routine diagnostic applications. ${ }^{56}$

\section{Conclusion and outstanding challenges}

In this review, we have outlined the current status of AMS in the English NHS, including national policies and guidance, the evidence base for intervention strategies, and issues of education, training, and improved diagnostic technologies. However, there are a number of outstanding challenges in the field of stewardship and AMR.
One important strategy to combat the potential threat of untreatable infection is to accelerate the development of novel antimicrobials, although this is unlikely to happen without extensive commercial and/or political incentives, such as tax breaks, government funding, financial rewards for specific outcomes, simplified regulatory requirements, or extended patents. ${ }^{5}$ One such example is the 2012 US Generating Antibiotic Incentives Now (GAIN) Act. Clearly, AMS will remain of critical importance to protect any future antimicrobials developed through such effort.

Another priority for future work is to define the optimal duration of antimicrobial prescribing, for example, whether antibiotic conservation through short-duration regimens is safe and effective in limiting the development of resistance. ${ }^{5}$ Additional strategies that have been suggested include the use of combinations of antibiotics from different classes (as is used in antiretroviral therapy for human immunodeficiency virus) or the cycling of firstchoice antibiotics in empirical prescribing guidelines to avoid prolonged exposure. ${ }^{5}$

Here we have summarized the current status and importance of AMS to the NHS in England, and outlined the evidence base for current and potential AMS programs. The ultimate success of AMS may well determine to a large degree the future scope, utility, and effectiveness of the English NHS.

\section{Disclosure}

The authors report no conflicts of interest in this work.

\section{References}

1. Guyer B, Freedman MA, Strobino DM, Sondik EJ. Annual summary of vital statistics: trends in the health of Americans during the 20th century. Pediatrics. 2000;106:1307-1317.

2. Spellberg B Dr. William H. Stewart: mistaken or maligned? Clin Infect Dis. 2008;47:294.

3. Pier GB. On the greatly exaggerated reports of the death of infectious diseases. Clin Infect Dis. 2008;47:1113-1114.

4. Fauci AS, Morens DM. The perpetual challenge of infectious diseases. N Engl J Med. 2012;366:454-461.

5. Annual Report of the Chief Medical Officer 2011. Volume 2. Available from: https://www.gov.uk/government/publications/chief-medicalofficer-annual-report-volume-2. Accessed February 20, 2014.

6. Smith R, Coast J. The true cost of antimicrobial resistance. BMJ. 2013;346:f1493.

7. Kessel AS, Sharland M. The new UK antimicrobial resistance strategy and action plan. BMJ. 2013;346:f1601.

8. Carlet J, Collignon P, Goldmann D, et al. Society's failure to protect a precious resource: antibiotics. Lancet. 2011;378:369-371.

9. Molstad S, Erntell M, Hanberger H, et al. Sustained reduction of antibiotic use and low bacterial resistance: 10-year follow-up of the Swedish Strama programme. Lancet Infect Dis. 2008;8:125-132.

10. Dellit TH, Owens RC, McGowan JE Jr, et al. Infectious Diseases Society of America and the Society for Healthcare Epidemiology of America guidelines for developing an institutional program to enhance antimicrobial stewardship. Clin Infect Dis. 2007;44:159-177. 
11. Barbut F, Jones G, Eckert C. Epidemiology and control of Clostridium difficile infections in healthcare settings: an update. Curr Opin Infect Dis. 2011;24:370-376.

12. O'Brien DJ, Gould IM. Maximizing the impact of antimicrobial stewardship: the role of diagnostics, national and international efforts. Curr Opin Infect Dis. 2013;26:352-358.

13. Davies SC, Fowler T, Watson J, Livermore DM, Walker D. Annual Report of the Chief Medical Officer: infection and the rise of antimicrobial resistance. Lancet. 2013;381:1606-1609.

14. Costelloe C, Metcalfe C, Lovering A, Mant D, Hay AD. Effect of antibiotic prescribing in primary care on antimicrobial resistance in individual patients: systematic review and meta-analysis. BMJ. 2010;340:c2096.

15. Bolan GA, Sparling PF, Wasserheit JN. The emerging threat of untreatable gonococcal infection. N Engl J Med. 2012;366:485-487.

16. Boucher HW, Talbot GH, Bradley JS, et al. Bad bugs, no drugs: no ESKAPE! An update from the Infectious Diseases Society of America. Clin Infect Dis. 2009;48:1-12.

17. Munoz-Price LS, Poirel L, Bonomo RA, et al. Clinical epidemiology of the global expansion of Klebsiella pneumoniae carbapenemases. Lancet Infect Dis. 2013;13:785-796.

18. Ashiru-Oredope D, Sharland M, Charani E, McNulty C, Cooke J. Improving the quality of antibiotic prescribing in the NHS by developing a new Antimicrobial Stewardship Programme: Start Smart - Then Focus. J Antimicrob Chemother. 2012;67 Suppl 1:i51-i63.

19. Nemeth J, Ledergerber B, Preiswerk B, et al. Multidrug-resistant bacteria in travellers hospitalized abroad: prevalence, characteristics, and influence on clinical outcome. J Hosp Infect. 2012;82:254-259.

20. Paltansing S, Vlot JA, Kraakman ME, et al. Extended-spectrum betalactamase-producing Enterobacteriaceae among travelers from The Netherlands. Emerg Infect Dis. 2013;19:1206-1213.

21. Wickramasinghe NH, Xu L, Eustace A, Shabir S, Saluja T, Hawkey PM. High community faecal carriage rates of CTX-M ESBL-producing Escherichia coli in a specific population group in Birmingham, UK J Antimicrob Chemother. 2012;67:1108-1113.

22. Nathwani D, Sneddon J, Patton A, Malcolm W. Antimicrobial stewardship in Scotland: impact of a national programme. Antimicrob Resist Infect Control. 2012;1:7.

23. Department of Health, Department for Environment, Food and Rural Affairs. UK Five Year Antimicrobial Resistance Strategy 2013-2018. Available from: https://www.gov.uk/government/uploads/system/ uploads/attachment_data/file/244058/20130902_UK_5_year_AMR_ strategy.pdf. Accessed February 20, 2014.

24. United States National Library of Medicine and National Institutes of Health. The path of least resistance. 1998. Available from: http://www. advisorybodies.doh.gov.uk/smac1.htm. Accessed February 20, 2014.

25. Department of Health. UK antimicrobial resistance strategy and action plan. 2000. Available from: http://www.dh.gov.uk/en/Publicationsandstatistics/Publications/PublicationsPolicyAndGuidance/DH_4007783. Accessed February 20, 2014.

26. Department of Health. The Health and Social Care Act 2008: Code of Practice for health and adult social care on the prevention and control of infections and related guidance. 2008. Available from: http://www. dh.gov.uk/en/Publicationsandstatistics/Publications/PublicationsPolicy AndGuidance/DH_110288. Accessed February 20, 2014.

27. McNulty CA. European Antibiotic Awareness Day 2012: general practitioners encouraged to TARGET antibiotics through guidance, education and tools. J Antimicrob Chemother. 2012;67:2543-2546.

28. Cooke J, Alexander K, Charani E, et al. Antimicrobial stewardship: an evidence-based, antimicrobial self-assessment toolkit (ASAT) for acute hospitals. J Antimicrob Chemother. 2010;65:2669-2673.

29. Ashiru-Oredope D, Hopkins S. Antimicrobial stewardship: English Surveillance Programme for Antimicrobial Utilization and Resistance (ESPAUR). J Antimicrob Chemother. 2013;68:2421-2423.

30. Pulcini C, Williams F, Molinari N, Davey P, Nathwani D. Junior doctors' knowledge and perceptions of antibiotic resistance and prescribing: a survey in France and Scotland. Clin Microbiol Infect. 2011;17:80-87.
31. Minen MT, Duquaine D, Marx MA, Weiss D. A survey of knowledge, attitudes, and beliefs of medical students concerning antimicrobial use and resistance. Microb Drug Resist. 2010;16:285-289.

32. van der Velden LB, Tromp M, Bleeker-Rovers CP, et al. Non-adherence to antimicrobial treatment guidelines results in more broad-spectrum but not more appropriate therapy. Eur J Clin Microbiol Infect Dis. 2012;31:1561-1568

33. National Prescribing Centre. A single competency framework for all prescribers. Available from: http://www.npc.nhs.uk/improving_safety/ improving_quality/. Accessed Accessed February 20, 2014.

34. Department of Health and Public Health England. Antimicrobial prescribing and stewardship competencies. Available from: https:// www.gov.uk/government/publications/antimicrobial-prescribing-andstewardship-competencies. Accessed February 20, 2014.

35. Cals JW, Boumans D, Lardinois RJ, et al. Public beliefs on antibiotics and respiratory tract infections: an Internet-based questionnaire study. Br J Gen Pract. 2007;57:942-947.

36. Akkerman AE, Kuyvenhoven MM, van der Wouden JC, Verheij TJ. Determinants of antibiotic overprescribing in respiratory tract infections in general practice. J Antimicrob Chemother. 2005;56:930-936.

37. Akkerman AE, Kuyvenhoven MM, van der Wouden JC, Verheij TJ. Analysis of under- and overprescribing of antibiotics in acute otitis media in general practice. J Antimicrob Chemother. 2005;56:569-574.

38. Stockley JM. European Antibiotic Awareness Day 2012: getting smart about antibiotics, a public-professional partnership. J Infect. 2012;65: 377-379.

39. McNulty CA, Nichols T, Boyle PJ, Woodhead M, Davey P. The English antibiotic awareness campaigns: did they change the public's knowledge of and attitudes to antibiotic use? J Antimicrob Chemother. 2010;65: $1526-1233$.

40. Francis NA, Butler CC, Hood K, Simpson S, Wood F, Nuttall J. Effect of using an interactive booklet about childhood respiratory tract infections in primary care consultations on reconsulting and antibiotic prescribing: a cluster randomised controlled trial. BMJ. 2009;339:b2885.

41. Moore M. Antibiotics: time to act. Br J Gen Pract. 2013;63:340-341.

42. Arnold SR, Straus SE. Interventions to improve antibiotic prescribing practices in ambulatory care. Cochrane Database Syst Rev. 2005;4:CD003539.

43. Gjelstad S, Hoye S, Straand J, Brekke M, Dalen I, Lindbaek M. Improving antibiotic prescribing in acute respiratory tract infections: cluster randomised trial from Norwegian general practice (prescription peer academic detailing (Rx-PAD) study). BMJ. 2013;347:f4403.

44. Gerber JS, Prasad PA, Fiks AG, et al. Effect of an outpatient antimicrobial stewardship intervention on broad-spectrum antibiotic prescribing by primary care pediatricians: a randomized trial. JAMA. 2013;309:2345-2352.

45. Davey P, Brown E, Charani E, et al. Interventions to improve antibiotic prescribing practices for hospital inpatients. Cochrane Database Syst Rev. 2013;4:CD003543.

46. Gaieski DF, Mikkelsen ME, Band RA, et al. Impact of time to antibiotics on survival in patients with severe sepsis or septic shock in whom early goal-directed therapy was initiated in the emergency department. Crit Care Med. 2010;38:1045-1053.

47. Schuetz P, Christ-Crain M, Thomann R, et al. Effect of procalcitoninbased guidelines vs standard guidelines on antibiotic use in lower respiratory tract infections: the ProHOSP randomized controlled trial. JAMA. 2009;302:1059-1066.

48. Albrich WC, Dusemund F, Bucher B, et al. Effectiveness and safety of procalcitonin-guided antibiotic therapy in lower respiratory tract infections in "real life": an international, multicenter poststudy survey (ProREAL). Arch Intern Med. 2012;172:715-722.

49. Liew YX, Lee W, Cai YY, et al. Utility and safety of procalcitonin in an antimicrobial stewardship program (ASP) in patients with malignancies. Eur J Clin Microbiol Infect Dis. 2012;31:3041-3046.

50. Hohn A, Schroeder S, Gehrt A, et al. Procalcitonin-guided algorithm to reduce length of antibiotic therapy in patients with severe sepsis and septic shock. BMC Infect Dis. 2013;13:158. 
51. Wacker C, Prkno A, Brunkhorst FM, Schlattmann P. Procalcitonin as a diagnostic marker for sepsis: a systematic review and meta-analysis. Lancet Infect Dis. 2013;13:426-435.

52. Saeed K, Dryden M, Bourne S, Paget C, Proud A. Reduction in antibiotic use through procalcitonin testing in patients in the medical admission unit or intensive care unit with suspicion of infection. J Hosp Infect. 2011;78:289-292.

53. Sauer S, Kliem M. Mass spectrometry tools for the classification and identification of bacteria. Nat Rev Microbiol. 2010;8:74-82.
54. Perez KK, Olsen RJ, Musick WL, et al. Integrating rapid pathogen identification and antimicrobial stewardship significantly decreases hospital costs. Arch Pathol Lab Med. 2013;137:1247-1254.

55. Geiger K, Brown J. Rapid testing for methicillin-resistant Staphylococcus aureus: implications for antimicrobial stewardship. Am J Health Syst Pharm. 2013;70:335-342.

56. Fricke WF, Rasko DA. Bacterial genome sequencing in the clinic: bioinformatic challenges and solutions. Nat Rev Genet. 2014;15(1): 49-55.

\section{Publish your work in this journal}

Infection and Drug Resistance is an international, peer-reviewed openaccess journal that focuses on the optimal treatment of infection (bacterial, fungal and viral) and the development and institution of preventive strategies to minimize the development and spread of resistance. The journal is specifically concerned with the epidemiology of antibiotic

\section{Dovepress}

resistance and the mechanisms of resistance development and diffusion in both hospitals and the community. The manuscript management system is completely online and includes a very quick and fair peerreview system, which is all easy to use. Visit http://www.dovepress.com/ testimonials.php to read real quotes from published authors.

Submit your manuscript here: http://www.dovepress.com/infection-and-drug-resistance-journal 